Article

\title{
New Strategies in the Cultivation of Olive Trees and Repercussions on the Nutritional Value of the Extra Virgin Olive Oil
}

\author{
Irene Dini ${ }^{1, *(\mathbb{D}, \text { Giulia Graziani }}{ }^{1, * \mathbb{C}}$, Anna Gaspari ${ }^{1}$, Francesca Luisa Fedele ${ }^{2}$, Andrea Sicari ${ }^{2}$, \\ Francesco Vinale ${ }^{3,4}$, Pierpaolo Cavallo ${ }^{5,6}$, , Matteo Lorito ${ }^{4,7}$ and Alberto Ritieni ${ }^{1}$ (I) \\ 1 Department of Pharmacy, University of Naples Federico II, Via Domenico Montesano 49, 80141 Napoli, Italy; \\ anna.gaspari@unina.it (A.G.); alberto.ritieni@unina.it (A.R.) \\ 2 LINFA SCARL. Via Zona Industriale Porto San Salvo, 89900 Vibo Valentia, Italy; \\ ricerca@laboratoriolinfa.it (F.L.F.); andrea@laboratoriolinfa.it (A.S.) \\ 3 Department of Veterinary Medicine and Animal Productions, University of Naples Federico II, \\ Via Federico Delpino 1, 80137 Napoli, Italy; francesco.vinale@unina.it \\ 4 Institute for Sustainable Plant Protection, National Research Council, Via Università 133, \\ 80055 Portici (NA), Italy; matteo.lorito@unina.it \\ 5 Department of Physics, University of Salerno, Via Giovanni Paolo II, 132, 84084 Fisciano (SA), Italy; \\ pcavallo@unisa.it \\ 6 Istituto Sistemi Complessi del Consiglio Nazionale delle Ricerche (ISC-CNR), 00185 Rome, Italy \\ 7 Department of Agricultural Science, University of Naples Federico II, Via Università 100, 80055 Portici, Italy \\ * Correspondence: irdini@unina.it (I.D.); giulia.graziani@unina.it (G.G.)
}

Academic Editors: Prokopios Magiatis and Derek J. McPhee

Received: 22 April 2020; Accepted: 10 May 2020; Published: 18 May 2020

\begin{abstract}
The health advantages of extra-virgin olive oil (EVOO) are ascribed mainly to the antioxidant ability of the phenolic compounds. Secoiridoids, hydroxytyrosol, tyrosol, phenolic acid, and flavones, are the main nutraceutical substances of EVOO. Applications of beneficial microbes and/or their metabolites impact the plant metabolome. In this study the effects of application of selected Trichoderma strains or their effectors (secondary metabolites) on the phenolic compounds content and antioxidant potential of the EVOOs have been evaluated. For this purpose, Trichoderma virens (strain GV41) and Trichoderma harzianum (strain T22), well-known biocontrol agents, and two their metabolites harzianic acid (HA) and 6-pentyl- $\alpha$-pyrone (6PP) were been used to treat plants of Olea europaea var. Leccino and var. Carolea. Then the nutraceutical potential of EVOO was evaluated. Total phenolic content was estimated by Folin-Ciocalteau's assay, metabolic profile by High-Resolution Mass spectroscopy (HRMS-Orbitrap), and antioxidant activity by DPPH and ABTS assays. Our results showed that in the cultivation of the olive tree, T22 and its metabolites improve the nutraceutical value of the EVOOs modulating the phenolic profile and improving antioxidants activity.
\end{abstract}

Keywords: Trichoderma spp.; EVOO; secondary metabolites; phenolic identification; phenolic content; HRMS-Orbitrap; antioxidant activity

\section{Introduction}

The health benefits of the extra-virgin olive oil are ascribed mainly to phenolic compounds, among which the most concentrated are lignans (pinoresinol, acetoxypinoresinol, hydroxypinoresinol, etc.) and secoiridoids (ligstroside, oleuropein, etc.), with the latter located only in the Oleaceae family [1]. Other phenolics in EVOO are flavonoids (luteolin, apigenin, etc.), phenolic alcohols (tyrosol, hydroxytyrosol, etc.), and phenolic acids (hydroxybenzoic acid, ferulic acid, etc.) [2]. These substances modulate aging-associated processes and have antitumor, antiviral, anti-atherogenic, anti-inflammatory, 
antihepatotoxic, hypoglycemic, immunomodulatory [3-6], and anti-autoimmune (i.e., rheumatoid arthritis) properties [7]. The quality and content of the phenolic compounds in EVOO vary significantly according to the olive cultivar, environmental factors (altitude, agricultural practices, and amount of irrigation), oil extraction conditions (heating, added water, malaxation, pressure, centrifugation systems) and storage conditions [8]. The superior quality of the extra virgin olive oil is linked to olive fruits free of damage caused by pests, so pesticide (insecticides, fungicides, and herbicides) applications are used to enhance the number and size of olives. Unfortunately, residues from pesticides can pass into EVOO and determine health risks. Therefore, analytical procedures are carried out to determine their dosage in the oil. Organic agriculture is an alternative to the use of pesticides. These environmental systems depend on ecosystem management. Organic products are considered healthier and safer than conventional; therefore, they are required by the consumers despite their higher costs than conventional products. In the $\mathrm{EU}$, subsidies were done to producers for compensating the lower incomes when they convert in organic the traditional cultivation (EC 2017) [9]. Biological control is one of the most appreciated alternatives against plant pathogens in a sustainable, environment-friendly strategy. The use of beneficial microbes have the benefit of the rhizosphere competence, allowing rapid establishment within the rhizosphere of a stable microbial community; suppression of pathogens by using a variety of mechanisms; overall improvement of plant health; plant growth promotion; enhancement of the nutrient availability and uptake, induction of host resistance similar to that stimulated by beneficial rhizobacteria, and positive change of the plant metabolome $[10,11]$. Trichoderma species are free-living fungi able to interact in the root, soil, and foliar environments with potential as biopesticides and biofertilizers [11,12]. They restore the beneficial balance of natural ecosystems by competing against the phytopathogens agents for space and nutrients [13]. They stimulate, in the plant, the production of secondary metabolites, including phenolic compounds, with health properties [14]. The commercial success of products containing these fungal antagonists can be attributed to the large volume of viable propagules that can be produced rapidly in several fermentation systems [15]. Biological diversity of the Trichoderma species produces a broad range of secondary metabolites; whose production varies according to the strain used [13]. Some of these biomolecules shown promising antifungal activity [16]. One factor that contributes to Trichoderma activities is related to the wide variety of metabolites that they produce. These metabolites have been found not only to directly inhibit the growth of pathogens, but also to increase disease resistance, enhance plant growth and modified plant metabolome [17]. Previous studies have shown that the Trichoderma T22 enhances the concentration of phenolics in the Vitis vinifera fruit and increases the tolerance of tomato plant to biotic and abiotic stresses by scavenging reactive oxygen species (ROS) and reutilizing oxidized glutathione and ascorbate $[18,19]$. It has been demonstrated that the Trichoderma GV41 improves antioxidant activity, total phenols concentration and profile in lettuce [14]. However, to date, nothing is known about the effects of these strains of Trichoderma on qualitative and quantitative profiles of the phenolic compounds in extra virgin olive oil. Therefore, the main objective of this study was to determine the possible impact of Trichoderma (T22 and GV41 on the nutraceutical value of the extra virgin olive oil produced by two Olea europaea varieties (Leccino and Carolea). Unfortunately, the use of the living fungus in agriculture is limited by the capacity of some strains to colonize every type of soils and plant roots, the impossibility of having directly proportional dose-response effects, and difficult storage conditions [20]. A solution to these problems is given using secondary metabolites of the Trichoderma. In this study, the ability of the tetrameric acid derivative with iron-binding activity (harzianic acid) and the food-grade volatile 6PP (pyrone 6-pentyl- $\alpha$-pyrone) of improving the nutraceutical quality of the EVOO was also evaluated.

\section{Results}

\subsection{Analyses of Phenolics}

Q Exactive Orbitrap LC-MS/MS method allowed the identification and the quantification of the phenolic compounds in the samples. The identification of the phenolic compounds was made by comparing the retention times (Rt) to the mass spectra of the purified compounds and the standards. 
The ligstroside not commercially available was quantified by using the oleuropein in place of the authentic standard. Table 1 shows the retention time (RT) of phenolics obtained by UPLC-MS/MS.

Table 1. Analytical parameters of phenolics identification; all compounds were monitored in negative mode.

\begin{tabular}{|c|c|c|c|c|c|c|c|}
\hline Phenolic Compounds & RT (min) & Formula & $\begin{array}{c}\text { Theoretical } \mathrm{m} / \mathrm{z} \\
\text { of Deprotonated } \\
\text { Molecular Ions } \\
{[\mathbf{M}-\mathbf{H}]^{-}}\end{array}$ & $\begin{array}{c}\text { Experimental } \mathrm{m} / \mathrm{z} \\
\text { of Deprotonated } \\
\text { Molecular ions } \\
{[\mathbf{M}-\mathbf{H}]^{-}} \\
\end{array}$ & $\begin{array}{l}\text { Calculated } \\
\text { Errors } \\
\Delta \text { ppm }\end{array}$ & Fragments & $\begin{array}{l}\text { Collision } \\
\text { Energy }(e V)\end{array}$ \\
\hline \multicolumn{8}{|c|}{ Phenolic acids } \\
\hline Vanillic acid & 4.30 & $\mathrm{C}_{8} \mathrm{H}_{8} \mathrm{O}_{4}$ & 167.03498 & 167.03522 & 1.44 & 152.01143 & 20 \\
\hline$p$-Coumaric acid & 9.71 & $\mathrm{C}_{9} \mathrm{H}_{10} \mathrm{O}_{5}$ & 163.04007 & 163.04028 & 1.29 & 119.05023 & 20 \\
\hline Cinnamic acid & 11.54 & $\mathrm{C}_{9} \mathrm{H}_{8} \mathrm{O}_{2}$ & 147.04515 & 147.04536 & 1.43 & 103.04501 & 20 \\
\hline Ferulic acid & 11.81 & $\mathrm{C}_{10} \mathrm{H}_{10} \mathrm{O}_{4}$ & 193.05063 & 193.05084 & 1.09 & 178.02685 & 20 \\
\hline 4-Hydroxybenzoic acid & 2.57 & $\mathrm{C}_{7} \mathrm{H}_{6} \mathrm{O}_{3}$ & 137.02442 & 137.02456 & 1.02 & 93.03431 & 12 \\
\hline 3-Hydroxybenzoic acid & 2.88 & $\mathrm{C}_{7} \mathrm{H}_{6} \mathrm{O}_{3}$ & 137.02442 & 137.02458 & 1.17 & 93.03431 & 12 \\
\hline \multicolumn{8}{|c|}{ Flavonoids } \\
\hline Apigenin & 19.12 & $\mathrm{C}_{15} \mathrm{H}_{10} \mathrm{O}_{5}$ & 269.04555 & 269.04597 & 1.56 & 225.05592 & 35 \\
\hline Luteolin & 19.07 & $\mathrm{C}_{15} \mathrm{H}_{10} \mathrm{O}_{6}$ & 285.04046 & 285.04106 & 2.10 & 133.02940 & 30 \\
\hline \multicolumn{8}{|c|}{ Lignans } \\
\hline (+) Pinoresinol & 17.00 & $\mathrm{C}_{20} \mathrm{H}_{22} \mathrm{O}_{6}$ & 357.13436 & 357.13487 & 1.43 & 151.03961 & 40 \\
\hline (+) 1-Acetoxypinoresinol & 19.10 & $\mathrm{C}_{22} \mathrm{H}_{24} \mathrm{O}_{8}$ & 415.13984 & 415.14007 & 0.55 & 415.13821 & 40 \\
\hline \multicolumn{8}{|c|}{ Phenolic Alcohols } \\
\hline Hydroxytyrosol (3,4 DHPEA) & 1.60 & $\mathrm{C}_{8} \mathrm{H}_{10} \mathrm{O}_{3}$ & 153.05572 & 153.05580 & 0.52 & 123.04561 & 12 \\
\hline Tyrosol ( $p$-HPEA) & 2.75 & $\mathrm{C}_{8} \mathrm{H}_{10} \mathrm{O}_{2}$ & 137.06080 & 137.06096 & 1.17 & 119.05022 & 12 \\
\hline \multicolumn{8}{|c|}{ Secoiridoids } \\
\hline Elenolic acid & 13.14 & $\mathrm{C}_{11} \mathrm{H}_{14} \mathrm{O}_{6}$ & 241.07176 & 241.07212 & 1.49 & 209.04573 & 10 \\
\hline Oleacein (3.4 DHPEA-EDA) & 16.14 & $\mathrm{C}_{17} \mathrm{H}_{20} \mathrm{O}_{6}$ & 319.11871 & 319.11898 & 0.85 & 301.1082 & 15 \\
\hline Oleuropein & 16.69 & $\mathrm{C}_{25} \mathrm{H}_{32} \mathrm{O}_{13}$ & 539.17701 & 539.17767 & 1.22 & 377.12393 & 20 \\
\hline Ligstroside & 18.25 & $\mathrm{C}_{25} \mathrm{H}_{32} \mathrm{O}_{12}$ & 523.18210 & 523.18279 & 1.32 & 361.12914 & 12 \\
\hline $\begin{array}{l}\text { Ligstroside-decarboxymethyl } \\
\text { aglycone oleocanthal } \\
\text { (p-HPEA-EDA) }\end{array}$ & 18.59 & $\mathrm{C}_{17} \mathrm{H}_{20} \mathrm{O}_{5}$ & 303.12380 & 303.12441 & 2.01 & 301.1082 & 12 \\
\hline Secologanoside & 19.49 & $\mathrm{C}_{16} \mathrm{H}_{21} \mathrm{O}_{11}$ & 389.1092 & 389.109258 & 0.59 & 345.1195 & 12 \\
\hline $\begin{array}{c}\text { Oleuropein-aglycone } \\
\text { mono-aldehyde } \\
\text { (3.4 DHPEA-EA) }\end{array}$ & 21.25 & $\mathrm{C}_{19} \mathrm{H}_{22} \mathrm{O}_{8}$ & 377.12419 & 377.12442 & 0.61 & 345.09790 & 12 \\
\hline $\begin{array}{l}p \text {-HPEA-EA (Ligstroside- } \\
\text { aglycone monoaldehyde) }\end{array}$ & 21.59 & $\mathrm{C}_{19} \mathrm{H}_{22} \mathrm{O}_{7}$ & 361.12145 & 361.12141 & -0.11 & 291.1122 & 21 \\
\hline
\end{tabular}

A new chromatographic method was applied for the quantification of individual secondary metabolites, whose validation parameters were reported in Table 2. Limits of detection (LODs) range was from 0.02 to $1.0 \mathrm{mg} / \mathrm{L}$, Limits of quantification (LOQs) 0.033 to $3.0 \mathrm{mg} / \mathrm{L}$, and the linearity range between 88.7 and $1 \%$.

Secoiridoids derivatives were the most representative phenolics in the two EVOO samples, and between these, the oleuropein-aglycone monoaldehyde, ligstroside-aglycone monoaldehyde, oleocanthal, and oleacein were the most abundant (Table 3).

The second group of phenolic compounds by concentration were phenolic alcohols (Table 4).

The third most abundant class of phenolic compounds were lignans (Table 5) followed by flavonoids (Table 6) and phenolic acids (Table 7).

Noteworthy was the content of luteolin in Carolea $_{\text {oil }}$ and the ability of Ha biostimulation to improve it. 
Table 2. Validation parameters of the quantification method.

\begin{tabular}{|c|c|c|c|c|c|}
\hline Phenolic Compounds & Linearity (mg/L) & $\mathbf{R}^{2}$ & $\operatorname{LOD}(\mathrm{mg} / \mathrm{L})$ & LOQ (mg/L) & $\begin{array}{l}\text { Intraday RSD } \% \\
(n=3), 50 \mathrm{mg} / \mathrm{L}\end{array}$ \\
\hline \multicolumn{6}{|c|}{ Phenolic Acids } \\
\hline$p$-Coumaric acid & $1-50$ & 1.000 & 0.100 & 0.300 & 1.8 \\
\hline Cinnamic acid & $1-50$ & 0.991 & 0.200 & 0.600 & 0.9 \\
\hline 4-Hydroxybenzoic acid & $1-50$ & 0.998 & 0.207 & 0.622 & 0.9 \\
\hline 3-Hydroxybenzoic acid & $1-50$ & 0.995 & 0.205 & 0.622 & 1.1 \\
\hline Apigenin & $0.5-50$ & 0.899 & 0.066 & 0.200 & 2.1 \\
\hline Luteolin & $0.5-50$ & 0.991 & 0.066 & 0.200 & 1.4 \\
\hline \multicolumn{6}{|c|}{ Lignans } \\
\hline (+) Pinoresinol & $1-50$ & 0.999 & 0.02 & 0.060 & 0.5 \\
\hline (+)1-Acetoxypinoresinol & $1-50$ & 0.899 & 0.233 & 0.700 & 1.5 \\
\hline \multicolumn{6}{|c|}{ Secoiridoids } \\
\hline Elenolic acid & $1-50$ & 0.991 & 0.333 & 1.000 & 0.7 \\
\hline Oleuropein & $1-50$ & 0.991 & 0.166 & 0.500 & 5.0 \\
\hline Ligstroside & $1-50$ & 0.991 & 0.166 & 0.500 & 4.0 \\
\hline Oleocanthal & $1-50$ & 0.899 & 0.416 & 1.250 & 3.0 \\
\hline Secologanoside & $1-50$ & 0.967 & 0.333 & 1.000 & 2.1 \\
\hline 3.4-DHPEA-EA (Oleuropein-aglycone monoaldehyde) & $1-50$ & 0.998 & 1.000 & 3.000 & 2.1 \\
\hline p-HPEA-EA (Ligstroside- aglycone monoaldehyde) & $1-50$ & 0.999 & 0.033 & 0.100 & 0.7 \\
\hline 3.4 DHPEA-EDA (Oleacein) & $1-50$ & 0.991 & 0.033 & 0.100 & 1.1 \\
\hline
\end{tabular}

Table 3. Content of secoiridoids in EVOO (mg/ $/ \mathrm{kg})$.

\begin{tabular}{|c|c|c|c|c|c|c|c|c|}
\hline & Oleuropein & Ligstroside & Secologanoside & e Elenolic Acid & p-HPEA-EA & $\begin{array}{l}\text { 3.4-DHPEA-EA } \\
\text { (Oleuropein-aglycone } \\
\text { monoaldehyde) }\end{array}$ & $\begin{array}{c}\text { p- HPEA-EDA } \\
\text { (Ligstroside-decarboxymethyl } \\
\text { aglycone) }\end{array}$ & $\begin{array}{l}\text { 3.4-DHPEA-EDA } \\
\text { (oleacein) }\end{array}$ \\
\hline \multicolumn{9}{|c|}{ Leccino cultivar } \\
\hline T22 & $0.051 \pm 0$ & $0.016 \pm 0.004$ & $0.022 \pm 0.003$ & $0.782 \pm 0.006$ & $113.34 \pm 0.234$ & $151.672 \pm 0.018$ & $113.34 \pm 0.234$ & $368.416 \pm 5.474$ \\
\hline $\mathrm{HA}$ & $0.053 \pm 0.003$ & $0.015 \pm 0.002$ & $0.083 \pm 0.008$ & $1.317 \pm 0.023$ & $144.889 \pm 1.349$ & $18.578 \pm 2.467$ & $144.889 \pm 1.349$ & $359.45 \pm 2.078$ \\
\hline 6PP & $0.053 \pm 0.001$ & $0.001 \pm 0.001$ & $0.004 \pm 0.001$ & $0.126 \pm 0.002$ & $15.661 \pm 0.343$ & $22.335 \pm 0.41$ & $15.661 \pm 0.343$ & $56.547 \pm 0.319$ \\
\hline Control & $0.046 \pm 0.003$ & $0.007 \pm 0.001$ & $0.01 \pm 0$ & $2.704 \pm 0.144$ & $103.342 \pm 0.553$ & $105.488 \pm 0.506$ & $103.342 \pm 0.553$ & $226.173 \pm 0.065$ \\
\hline \multicolumn{9}{|c|}{ Carolea cultivar } \\
\hline HA & $0.069 \pm 0.001$ & $0.023 \pm 0.002$ & $0.181 \pm 0.005$ & $5.555 \pm 0.071$ & $119.875 \pm 0.849$ & $166.79 \pm 0.291$ & $119.875 \pm 0.849$ & $52.865 \pm 0.406$ \\
\hline $6 \mathrm{PP}$ & $0.053 \pm 0.001$ & $0.001 \pm 0.001$ & $0.004 \pm 0.001$ & $2.226 \pm 0.01$ & $108.81 \pm 1.891$ & $133.9 \pm 1.021$ & $108.81 \pm 1.891$ & $60.665 \pm 0.169$ \\
\hline Control & $0.377 \pm 0.431$ & $0.038 \pm 0.006$ & $0.124 \pm 0.009$ & $1.28 \pm 0.237$ & $108.172 \pm 15.044$ & $210.729 \pm 6.933$ & $228.172 \pm 15.044$ & $25.634 \pm 6.69$ \\
\hline
\end{tabular}

Table 4. Content of phenolic alcohols in EVOO (mg/kg).

\begin{tabular}{ccc}
\hline & 3.4 DHPEA (Hydroxytyrosol) & $p$-HPEA (Tyrosol) \\
\hline Leccino cultivar & & \\
T22 & $0.928 \pm 0.008$ & $155.108 \pm 0.731$ \\
GV41 & $0.498 \pm 0.016$ & $164.541 \pm 0.932$ \\
HA & $0.535 \pm 0.01$ & $146.029 \pm 0.881$ \\
6PP & $0.683 \pm 0.005$ & $228.288 \pm 2.377$ \\
Control & $0.636 \pm 0.007$ & $52.657 \pm 0.562$ \\
Carolea cultivar & & \\
T22 & $0.308 \pm 0.007$ & $72.356 \pm 0.893$ \\
GV41 & $0.294 \pm 0.014$ & $74.904 \pm 3.824$ \\
HA & $0.174 \pm 0.002$ & $42.38 \pm 0.75$ \\
6PP & $0.238 \pm 0.003$ & $27.106 \pm 0.901$ \\
Control & $0.263 \pm 0.009$ & $33.916 \pm 0.403$ \\
\hline
\end{tabular}


Table 5. Content of lignans in EVOO (mg/kg).

\begin{tabular}{ccc}
\hline & (+)-Pinoresinol & (+)-1-Acetoxypinoresinol \\
\hline Leccino cultivar & & \\
T22 & $0.855 \pm 0.024$ & $38.972 \pm 1.817$ \\
GV41 & $0.033 \pm 0.001$ & $3.655 \pm 0.108$ \\
HA & $0.799 \pm 0.007$ & $39.227 \pm 0.554$ \\
6PP & $0.104 \pm 0.003$ & $8.715 \pm 0.321$ \\
Control & $1.608 \pm 0.01$ & $49.807 \pm 0.558$ \\
Carolea cultivar & & \\
T22 & $0.376 \pm 0.001$ & $33.433 \pm 0.882$ \\
GV41 & $0.276 \pm 0.003$ & $20.821 \pm 0.511$ \\
HA & $0.744 \pm 0.02$ & $43.291 \pm 0.269$ \\
6PP & $0.517 \pm 0.005$ & $33.547 \pm 0.516$ \\
Control & $0.298 \pm 0.063$ & $18.967 \pm 0.461$ \\
\hline
\end{tabular}

Table 6. Content of flavonoids in EVOO (mg/kg).

\begin{tabular}{ccc}
\hline & Luteolin & Apigenin \\
\hline Leccino cultivar & & \\
T22 & $0.634 \pm 0.005$ & $0.075 \pm 0.001$ \\
GV41 & $0.244 \pm 0.012$ & $0.012 \pm 0$ \\
HA & $0.835 \pm 0.009$ & $0.086 \pm 0.001$ \\
6PP & $0.08 \pm 0.002$ & $0.01 \pm 0$ \\
Control & $0.52 \pm 0.015$ & $0.091 \pm 0$ \\
Carolea cultivar & & \\
T22 & $2.749 \pm 0.009$ & $0.188 \pm 0.007$ \\
GV41 & $1.841 \pm 0.004$ & $0.102 \pm 0.001$ \\
HA & $8.505 \pm 0.002$ & $0.395 \pm 0.005$ \\
6PP & $2.261 \pm 0.047$ & $0.179 \pm 0.003$ \\
Control & $2.045 \pm 0.346$ & $0.103 \pm 0.01$ \\
\hline
\end{tabular}

Table 7. Content of phenolic acids in EVOO $(\mathrm{mg} / \mathrm{kg})$.

\begin{tabular}{|c|c|c|c|c|c|c|}
\hline & $\begin{array}{l}\text { 4-Hydroxy } \\
\text { Benzoic Acid }\end{array}$ & $\begin{array}{c}\text { 3-Hydroxy } \\
\text { Benzoic Acid }\end{array}$ & Vanillic Acid & p-Coumaric Acid & Cinnamic Acid & Ferulic Acid \\
\hline \multicolumn{7}{|c|}{ Leccino cultivar } \\
\hline GV41 & $0.027 \pm 0.002$ & $0.02 \pm 0.002$ & $0.08 \pm 0.001$ & $0.109 \pm 0.005$ & $0.023 \pm 0.001$ & $0.036 \pm 0.001$ \\
\hline HA & $0.501 \pm 0.013$ & $0.055 \pm 0.01$ & $0.599 \pm 0.011$ & $0.373 \pm 0.004$ & $0.165 \pm 0.003$ & $0.179 \pm 0.002$ \\
\hline $6 \mathrm{PP}$ & $0.044 \pm 0.001$ & $0.007 \pm 0$ & $0.057 \pm 0.001$ & $0.036 \pm 0.001$ & $0.018 \pm 0.001$ & $0.019 \pm 0$ \\
\hline $\mathrm{T} 22$ & $0.166 \pm 0.001$ & $0.218 \pm 0.004$ & $1.142 \pm 0.006$ & $1.23 \pm 0.004$ & $0.361 \pm 0.014$ & $0.38 \pm 0.003$ \\
\hline GV41 & $0.226 \pm 0.003$ & $0.139 \pm 0.005$ & $0.698 \pm 0.002$ & $0.824 \pm 0.002$ & $0.196 \pm 0.001$ & $0.294 \pm 0.003$ \\
\hline HA & $0.345 \pm 0.006$ & $0.437 \pm 0.008$ & $2.527 \pm 0.032$ & $3.805 \pm 0.001$ & $0.759 \pm 0.009$ & $0.888 \pm 0.011$ \\
\hline $6 P P$ & $0.25 \pm 0.008$ & $0.174 \pm 0.002$ & $1.013 \pm 0.004$ & $1.012 \pm 0.021$ & $0.344 \pm 0.005$ & $0.313 \pm 0.001$ \\
\hline Control & $0.308 \pm 0.045$ & $0.119 \pm 0.003$ & $0.583 \pm 0.108$ & $0.915 \pm 0.155$ & $0.197 \pm 0.019$ & $0.307 \pm 0.007$ \\
\hline
\end{tabular}

\subsection{Phenol Content and Antioxidant Activity}

As shown in Figure 1, the EVOO obtained from Leccino variety olives had the highest content of phenols $\left(\mathrm{EVOO}_{\text {Leccino }}: 133.662 \mathrm{mg} / \mathrm{kg}^{-1} ; \mathrm{EVOO}_{\text {Carolea }}: 77.871 \mathrm{mg} \cdot \mathrm{kg}^{-1}\right)$. The treatment of the Carolea olive trees with the biocontrol agent $6 \mathrm{PP}$, compared to the untreated trees, improved the concentration of phenols in EVOO (+22\%), followed by HA $(+18 \%)$, and T22 $(+7 \%)$, only the treatment with the living fungus GV41 decreased their concentration (-16\%) (Figure 1).

In Leccino EVOO, the highest concentration of phenols occurred in the oil produced from olives obtained by treating trees with HA $(+23 \%)$, followed by T22 (+7\%). On the contrary, the treatment of the olive trees with GV41 and 6PP decreased their concentration: $-4 \%$ and $-11 \%$, respectively. (Figure 2). 


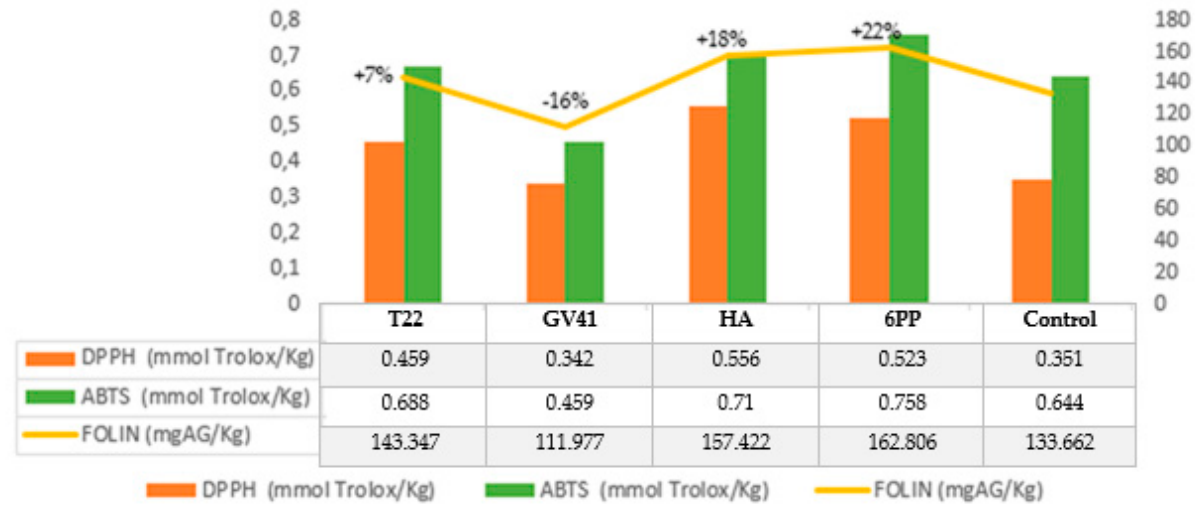

Figure 1. Phenolic content and antioxidant activity in the EVOO obtained by Carolea olives.

DPPH and ABTS assays were used to determine the antioxidant activity of samples. A positive correlation was found between phenolic concentration and antioxidant activity measured by the ABTS test in all oil samples $\left(\right.$ Leccino $_{\text {oil }}=0.970322$; Cororea $\left._{\text {oil }}=0.757275\right)$. Concerning the correlation between phenolic concentration and antioxidant activity measured by DPPH test, it was positive (0.91454) in Leccino $_{\text {oil }}$ and negative in Corolea ${ }_{\text {oil }}(-0.09952)$.

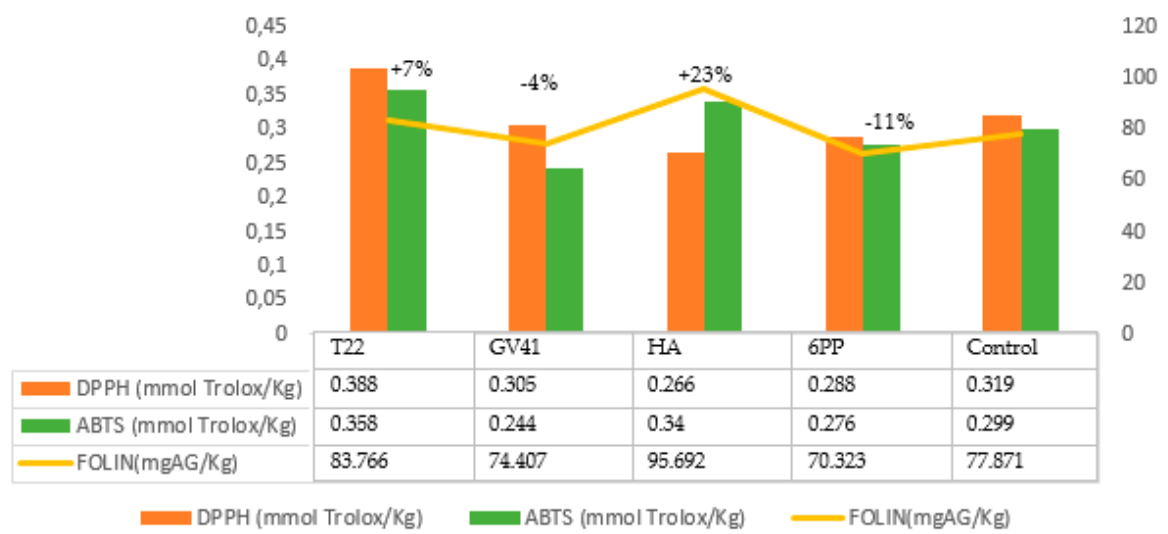

Figure 2. Phenolic content and antioxidant activity in the EVOO obtained by Leccino olives.

\subsection{Secoiridoids and Phenolic Alcohols Correlation}

Significant correlation indexes correlated secoiridoids and phenolic alcohols (EVOO Leccino -0.7 and EVOO Carolea +0.6 ). These indexes were obtained by correlating the sum of the concentrations of the four most representative secoiridoids (oleuropein-aglycone monoaldehyde+ ligstroside-aglycone monoaldehyde + oleocanthal + oleacein) with the sum of the two phenolic acids (tyrosol + OHTyrosol) (Figure 3). The " + " sign indicated that only a small part of secoiridoids degraded.
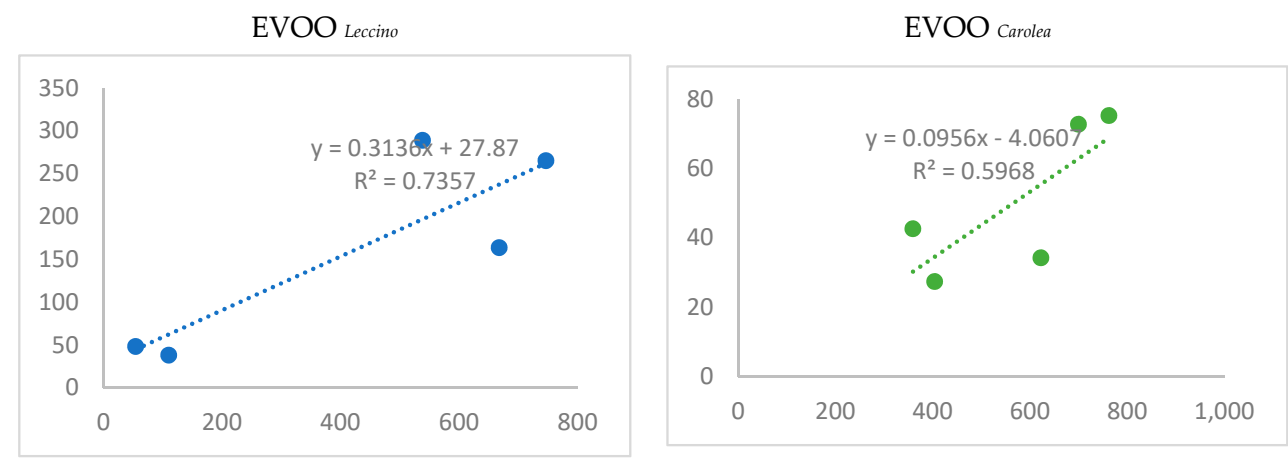

Figure 3. Correlation graphs of secoiridoids and phenolic alcohols. 


\subsection{Variation (\%) of the Most Representative Phenolics}

T22 strain determined in both oil samples an increase of the oleuropein-aglycon mono aldehyde of $\cong 45 \%$. In the EVOO Carolea, was shown a remarkable negative variation (\%) of ligstroside decarboxymethyl-aglycone (Figure 4).

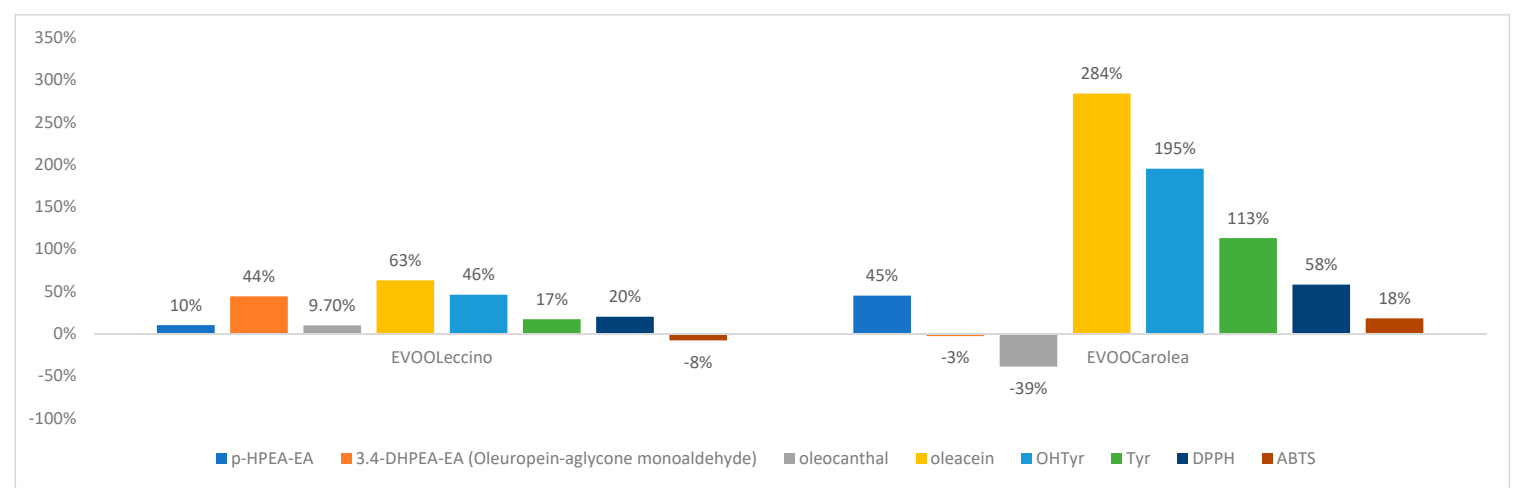

Figure 4. Variation (\%) of the most representative secoiridoids, their degradation products, and antioxidant activity in EVOOs obtained from olive tree treated with $\mathrm{T} 22$ strains.

HA treatment influenced flavonoid production in both monovarietal oils. The antioxidant activity of $\mathrm{EVOO}_{\text {Carolea }}$ was higher than $\mathrm{EVOO}_{\text {Leccino }}$ (Figure 5).

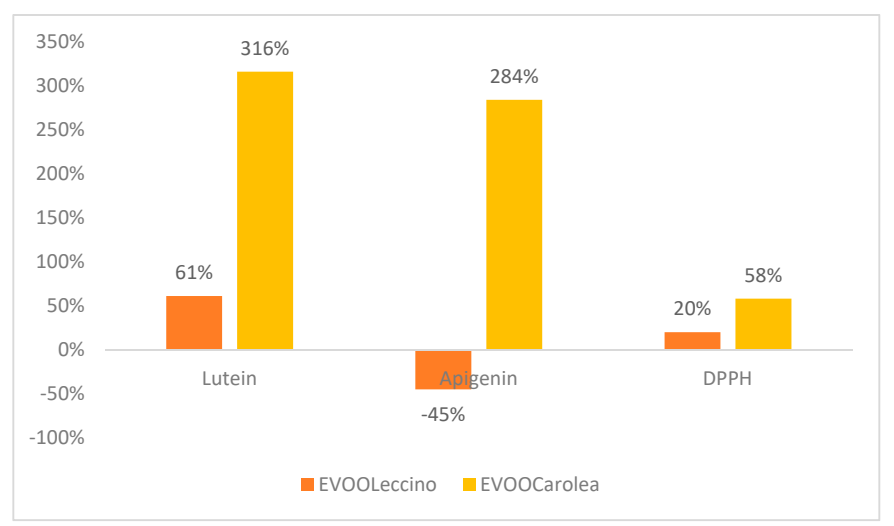

Figure 5. Variation (\%) of flavonoids and antioxidant activity measured by DPPH test in EVOOs obtained from olive tree treated with HA.

The 6PP biostimulation interfered with the production of the flavonoids and the lignans in the olives (Figure 6).

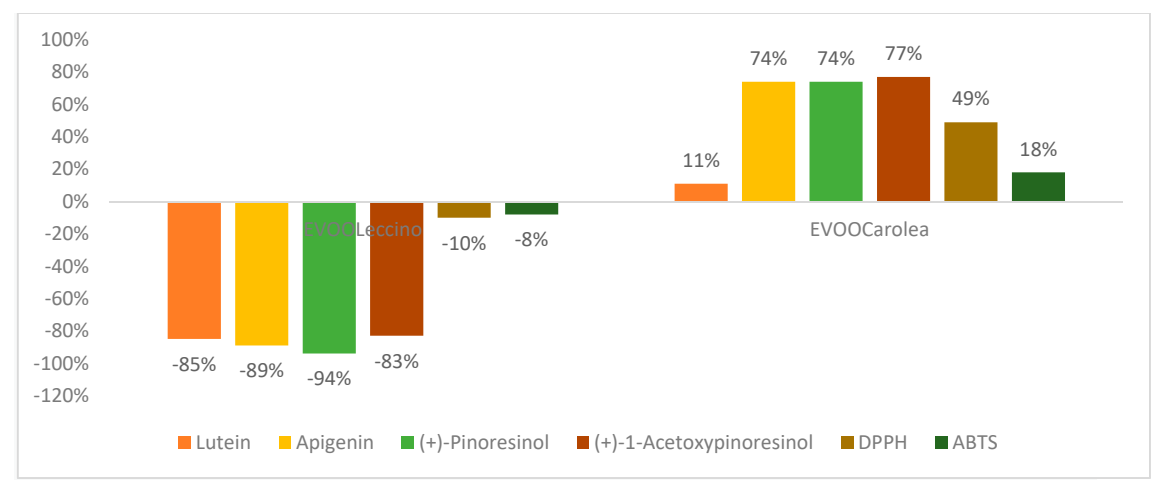

Figure 6. Variation (\%) of flavonoids, lignans and antioxidant activity in the EVOO samples obtained from olive tree treated with $6 \mathrm{PP}$. 
The total phenolic content was strongly affected by variations of the concentration of oleacein, tyrosol and apigenin (Figure 7).

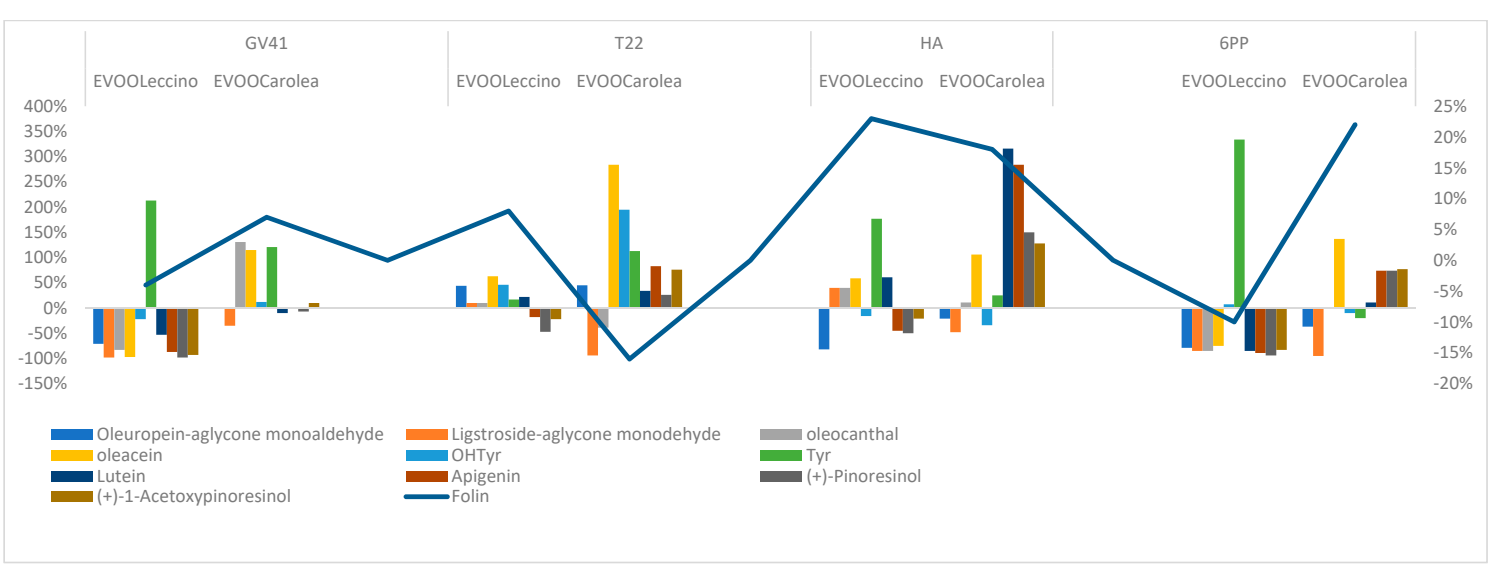

Figure 7. Variation (\%) of the phenolic class of compounds and total phenol content in the EVOO samples.

\section{Discussion}

Two monovarietal EVVOs olives were analyzed to determine the possible impact on their nutraceutical properties when biocontrol strategy was used in the fields. This goal was obtained by treating two monovarietal olive trees (Olea europaea var. Leccino and Olea europaea var Carolea) with two strains of Trichoderma (GV41 and T22), and their metabolites HA and 6PP and evaluating the total content of phenols in the oil, determining the single phenol quality and quantity and comparing these data with the antioxidant activity of the oils. A remarkable variability was found in phenolic composition between the two sets of monovarietal EVOOs analyzed. The phenolic identification was obtained by using an Orbitrap platform in MS and MS/MS levels, and phenolic quantification was performed by using a UPLC-MS technology. The quantification method was validated in terms of linearity, precision, and sensitivity. The correlation factor of the calibration curve $\cong 1$ established the first one, LODs, and the LOQs confirmed method sensitivity, and the relative standard deviation (RSD) $<10 \%$ validated the repeatability. Nine secoiridoids, two phenolic alcohols, two lignans, two flavonoids, and six phenolic acids were characterized comparing the mass spectra with standards, except the ligstroside whose identification occurred comparing mass data with literature data, [21] and the hydroxybenzoic acid isomers, for which the retention times and the mass spectra were used. In all olive oils, the secoiridoid derivatives were the most abundant phenols, followed by phenolic alcohols, flavonoids, and phenolic acids. The lignans and the flavonoids were in the aglycon form since they degrade during the malaxation process. A significant correlation index between secoiridoids and phenolic alcohols (Figure 3) confirmed that tyrosol and the OHtyrosol were degradation products of ligstroside and oleuropein [22]. All biostimulant treatments, increased the total polyphenol

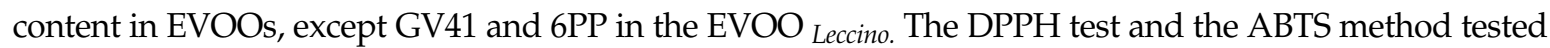
the antioxidant activity. The DPPH detected the ability of an antioxidant to transfer one electron to reduce any compound. The ABTS method determined the aptitude of the antioxidant to quench free radicals by hydrogen donation [23]. In this study, a significative correlation was found between the total phenolic content, and both tests used to determine the antioxidant activity. The DPPH measures were higher than that obtained with the ABTS test in the samples containing higher concentrations of flavonoids, $O$-diphenols and secoiridoids since DPPH test overestimates slow reacting antioxidants with many phenol groups as lutein, OHTyrosol and secoiridoid derivatives, able to donate hydrogen and improve radical stability by forming an intramolecular hydrogen bond between the free hydrogen of phenoxyl radicals, therefore the ABTS method is the best for the determination of the antioxidant activity in the oil [24]. The T22 biostimulation interferes above all with the production of secoiridoids in the olive. In both oil samples were found an increase of the oleuropein-aglycon mono aldehyde. A decreased concentration of ligstroside decarboxymethyl-aglycone was shown in the EVOO Carolea, probably due to transformation 
in its degradation product (tyrosol) (Figure 4). The biostimulation with the T22 strain enhanced the concentration of the total phenolic content of 7\% in both oil samples (Figures 1 and 2). This increase determines the growth of the antioxidant activity of $\cong 20 \%(\mathrm{DPPH}=22 \%$; ABTS $=20 \%)$ in the EVOO Leccino, $_{\text {, }}$ (Figure 2) and different measures of antioxidant activity in the EVOO Corolea, (Figure 1) according to the method used to determine it (DPPH test $=31 \%$ and ABTS test $=4 \%$ ) (Figure 4 ), since the higher concentration of secoiridoids and flavonoids in EVOO Carolea than EVOO Leccino, were overestimated in the DPPH method. The biostimulation with HA increased the phenolic content (particularly the flavonoidic fraction) in both monovarietal oils (Figure 5). The higher concentration of flavonoids in EVOO Carolea than

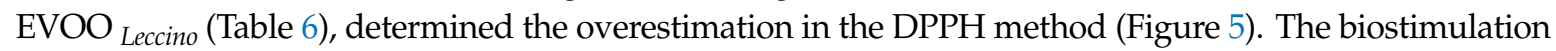

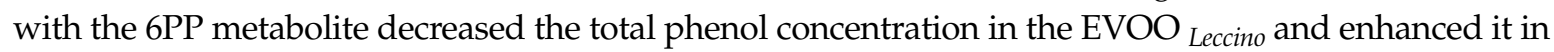
the EVOO Corolea (Figures 1 and 2). Consequently, the antioxidant activity decreased in the EVOO Leccino and improved in the EVOO Corolea. more than the control (Figure 6). The different variations of the polyphenol classes concentrations under the microbe or the microbe metabolites biostimulation (Figure 7) suggested that the nutraceutical properties [25] of the EVOO depended on the biostimulant used to grow olive trees (Figure 8). The biostimulation with T22 mainly enhanced the concentration of the secoiridoid fraction of phenols. As known, oleuropein is commercially available as a food supplement used to prevent the oxidation and the inflammatory damage, the cardiovascular and the cancer diseases, and as antiviral and antimicrobial agents [26]. Instead, the HA metabolite increased the flavonoids in the EVOOs. Luteolin has showed antitumorigenic, antimutagenic, antioxidative, immunomodulatory, and anti-inflammatory properties useful in cancer, cardiovascular diseases, and neurodegenerative pathologies prevention $[27,28]$. Finally, the 6PP metabolite improved lignans concentration in the EVOOs. Pinoresinol and acetoxypinoresinol intake has been related to LDL oxidation prevention, and health properties correlate to estrogen hormonal disfunction such as protection against cancer (prostate and breast) [29].

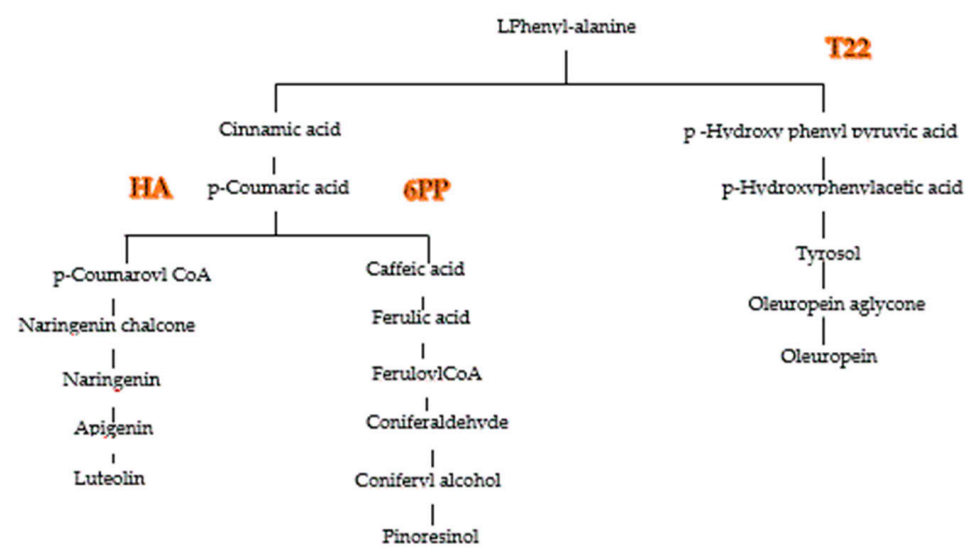

Figure 8. Interferences of Trichoderma T22 and its metabolites (HA and 6PP) on Shikimate pathway [23,30,31].

\section{Materials and Methods}

\subsection{Study Area}

This study was carried out in two experimental sites situated in Calabria, the most southern region of the Italian peninsula (ranges between $38^{\circ} 12^{\prime}$ and $40^{\circ}$ latitude North and between $16^{\circ} 30^{\prime}$ and $17^{\circ} 15^{\prime}$ longitude East). The provinces of Calabria are: Catanzaro (CZ, regional capital), Reggio Calabria, Cosenza (CS), Crotone (KR), and Vibo Valentia (VV). The two experimental sites are in the villages of Cariati (CS), and Roccabernarda (KR). The climate of this Region is predominantly Mediterranean, temperatures are very mild, especially in the coastal plains. In the summer the heat is shared by the entire regional territory and only the altitude mitigates the heat or the breezes; peaks of over $35^{\circ} \mathrm{C}$ are common. In the case of invasions of very hot African air, the temperatures exceed the $40{ }^{\circ} \mathrm{C}$ threshold. In Winter, on the other hand, temperatures remain mild with maxima greater than $10^{\circ} \mathrm{C}$ on the coasts 
and cold in the internal areas and in the mountains, where the snow falls abundantly, and above $1000 \mathrm{~m}$ can persist throughout the period from December to March.

\subsection{Plant Material}

The possible impact of bioformulates was tested on two cultivars of Olea europaea: Leccino and Carolea. Plant material were given by Dr. Andrea Sicari (LINFA scarl, Vibo Valentia, Italy).

Plants (15 years old) in excellent nutritional and phytosanitary status with an adequate number of fruiting branches and a low ratio of wood and leaves were used for experimental purposes. The experimental field contained 20 plants split in 12 rows ( 3 rows per treatment). Six treatments were applied starting from February until July after plants sprouted. Each bioformulate $\left(10^{-6} \mathrm{M} \mathrm{HA}\right.$, $10^{-6} \mathrm{M} 6 \mathrm{PP}, 10^{6} \mathrm{ufc} / \mathrm{mL}$ GV41, and $10^{6} \mathrm{ufc} / \mathrm{mL} \mathrm{T22}$ ) and one control sample (water treatment) were applied to the root system (drenching around the root system at $10 \mathrm{~cm}$ deep) and the leaves $(10 \mathrm{~L} \mathrm{per} \mathrm{row}$ of which $5 \mathrm{~L}$ was spray and $5 \mathrm{~L}$ was drenching).

\subsection{Fungal Material}

Biological Control laboratories of the University of Naples Federico II provide the Trichoderma strains. The strains Trichoderma harzianum (T22 and GV41), and Trichoderma harzianum (M10 Trichoderma harzianum Rifai, anamorph ATCC ${ }^{\circledR}$ 20847 ${ }^{\mathrm{TM}}$, (LGC Standards S.r.l., Sesto San Giovanni, Mi Italy) were maintained on potato 125 dextrose agar (HiMedia, Laboratories Mumbai, India) and shielded with sterilized mineral oil (Sigma Aldrich, St. Louis, MO, USA).

\subsection{Isolation and Characterization of Harzianic Acid}

The Trichoderma strains M10 was used to produce the bioactive molecules. Mycelia were inoculated into $1 \mathrm{~L}$ of sterile potato dextrose broth (PDB, HiMedia Mumbai, India). Cultures of each strain were grown for 30 days at $25^{\circ} \mathrm{C}$, and then vacuum-filtered through filter paper (Whatman No. 4, Brentford, UK). Ethyl acetate (EtOAc) was used to extract the filtrate $(2 \mathrm{~L})$. Organic fractions were dried with $\mathrm{Na}_{2} \mathrm{SO}_{4}$ and the solvent evaporated in vacuum at $35^{\circ} \mathrm{C}$. The red residue obtained from $\mathrm{M} 10$ was dissolved in $\mathrm{CHCl}_{3}$ and extracted three-times with $\mathrm{NaOH} 2 \mathrm{M}$. Harzianic acid (HA) then precipitated with $\mathrm{HCl} 2 \mathrm{M}$. The solid was recovered (135mg), solubilized and subjected to RP-18 vacuum chromatography (20 g Si gel RP-18, 40-63 $\mu \mathrm{m}$ Sigma Aldrich, St. Louis, MO), eluting with a gradient of methanol $(\mathrm{MeOH}): \mathrm{H}_{2} \mathrm{O}: \mathrm{CH}_{3} \mathrm{CN}$ (0.5:9:0.5/v:v:v to 10:0:0/v:v:v). After separation, approximately $45 \mathrm{mg}$ of pure HA was collected. The compounds were detected spectrophotometrically on TLC (UV: $\lambda 254$ or $\lambda 366 \mathrm{~nm}$ ) and by dipping the plates in a $5 \%(w / v)$ ethanol solution of $2 \mathrm{M} \mathrm{H}_{2} \mathrm{SO}_{4}$ and heating at $110{ }^{\circ} \mathrm{C}$ for $10 \mathrm{~min}$. The purified metabolites were characterized by NMR (Bruker AM 400 spectrometer; Bruker, Billerica, Massachusetts, USA) operating at $400(1 \mathrm{H}) \mathrm{MHz}$ using residual and deuterated solvent peaks as a reference standard or by LC-MS/MS QTOF (Agilent Technologies, Santa Clara, CA, USA) with a dual ESI (Electrospray Ionization) source, coupled to a DAD (Diode-Array Detection; Agilent Technologies, Santa Clara, CA, USA).

\subsection{Oil Production}

The oils samples were cold produced at a semi-industrial scale in a local two-phase mill. It was kept at a constant temperature $\left(10 \pm 2{ }^{\circ} \mathrm{C}\right)$ in dark bottles without headspace until analysis.

\subsubsection{Chemicals}

All the chemicals used are from Sigma Aldrich St. Louis, MO, USA, unless specified differently.

\subsubsection{Extraction of Phenolic Compounds from Olive Oil}

The method proposed by Vasquez Roncero [32] was used. In $25 \mathrm{~mL}$ hexane were put $25 \mathrm{~g}$ oil. $15 \mathrm{~mL}$ methanol:water $(3: 2 v / v)$ extracted the polar in three times. The extracts combined were treated once with $25 \mathrm{~mL}$ hexane. The solvent was evaporated in a rotary evaporator (Büchi, Switzerland) at $40^{\circ} \mathrm{C}$. 
The insoluble residue was abundantly washed with $\mathrm{CH}_{3} \mathrm{OH}$ and filtered through $0.2 \mu$ m nylon filter and immediately stored at $-18{ }^{\circ} \mathrm{C}$ until analysis.

\subsubsection{Ultra High Pressure Liquid Chromatograph}

Polyphenol compounds were isolated and quantified by an Ultra High Pressure Liquid Chromatograph (UHPLC, Thermo Fisher Scientific, Waltham, MA, USA) equipped with a Dionex Ultimate 3000 degassing system, a quaternary UHPLC pump (Thermo Fisher Scientific, Waltham, MA, USA) working at 1250 bar, and a column (Thermo Scientific, Waltham, MA, USA) Accucore aQ $2.6 \mu \mathrm{m}(100 \times 2.1 \mathrm{~mm})$ in a thermostated compartment $\left(\mathrm{T}=30^{\circ} \mathrm{C}\right) .5 \mu \mathrm{L}$ of the sample was injected. The eluent phase consists of a gradient programmed as follows: 0 to $5 \mathrm{~min}-5 \%$ of phase B, $25 \mathrm{~min}-40 \%$ of phase B, $25.1 \mathrm{~min}-100 \%$ of phase B, $27 \mathrm{~min}-100 \%$ of phase $\mathrm{B}, 27.1 \mathrm{~min}-5 \%$ of phase $\mathrm{B}, 35 \mathrm{~min}-5 \%$ of phase $\mathrm{B}, 31 \mathrm{~min}-0 \%$ of phase $\mathrm{B}$ where phase $A$ was $\mathrm{H}_{2} \mathrm{O} 0.1 \%$ of acetic acid and phase $B$ was acetonitrile. The flow rate was $0.4 \mathrm{~mL} / \mathrm{min}$.

\subsection{Mass Spectrometry Analysis}

A Q Exactive Orbitrap LC-MS/MS (Thermo Fisher Scientific, Waltham, MA, USA) was used for experimental purposes provided of an ESI source (HESI II, Thermo Fisher Scientific, Waltham, MA, USA) [spray voltage $-3.0 \mathrm{kV}$, capillary temperature $200{ }^{\circ} \mathrm{C}$, auxiliary gas $\left(\mathrm{N}_{2}>95 \%\right)^{15}$, sheath gas $\left(\mathrm{N}_{2}>95 \%\right)^{30}$, auxiliary gas heater temperature $305{ }^{\circ} \mathrm{C}$ and S-lens RF level 50]. The mass detection was obtained in two acquisition modes: negative-ion modes (full scan; mass resolving power 35,000 full width at half maximum (at $\mathrm{m} / \mathrm{z} 200$ ), the automatic gain control target $1 \times 105$ ions for a maximum injection time of $200 \mathrm{~ms}$, and scan range 100-1500 m/z, scan rate $2 \mathrm{~s}^{-1}$ ) and targeted selected ion monitoring [15 s-time window, quadrupole isolation window $1.2 \mathrm{~m} / \mathrm{z}$, and resolution power 35,000 full width at half maximum (at $m / z 200)]$.

\subsection{Validation of the Method Used to Quantify Single Phenols}

Method was validated following AOAC instructions (AOAC 2012) [33]. The parameters analyzed were linearity, LOD, LOQ, repeatability, and reproducibility. Three points (in triplicate) were used to build the calibration curves of each compound. Method linearity was obtained from the regression coefficient of the calibration curve LOD (Limits of detection) and LOQ limits of quantification were calculated from the regression curve. Nine different concentrations of each phenolic standard three times gave intraday repeatability.

$$
\text { LODs }=3 \times \frac{\text { standard deviation }}{\text { angular coefficient }} ; \text { LOQs }=10 \times \frac{\text { standard deviation }}{\text { angular coef ficient }}
$$

\subsection{Total Phenolic Compounds}

The total polyphenols amount was evaluated by using the Folin-Ciocalteau's assay as reported by Singleton and Rossi (1965) [34]. In a falcon (15 mL), $2.5 \mathrm{~mL} \mathrm{dd} \mathrm{H}_{2} \mathrm{O}$ and $625 \mu \mathrm{L}$ methanolic extract, $625 \mu \mathrm{L}$ of Folin-Ciocalteau's phenol reagent were shaken. After $6 \mathrm{~min}, 6.25 \mathrm{~mL}$ of $7 \% \mathrm{Na} 2 \mathrm{CO} 3$ solution was added to the mixture. The solution was diluted with $5 \mathrm{~mL}$ dd $\mathrm{H}_{2} \mathrm{O}$ and mixed. The absorbance (Lambda 25, PerkinElmer, Italy) of reagent blank was determined at $760 \mathrm{~nm}$ by spectrophotometer after incubation for $90 \mathrm{~min}$ at room temperature. All biological replicates of samples were analyzed in triplicate. Total phenolic content was expressed as mg gallic equivalents (GAE)/kg FW.

\subsection{Antioxidant Activity Measurements}

DPPH method. 2,2-Diphenyl-1-picrylhydrazyl (DPPH) radical-scavenging capacity was measured using the method described by Brand-Williams et al. (1995) [35]. Fraction aliquots (20 $\mu \mathrm{L})$ were added to $3 \mathrm{~mL}$ of DPPH solution $\left(6 \times 10^{-5} \mathrm{~mol} / \mathrm{L}\right)$ and the absorbance was determined at $\lambda 517 \mathrm{~nm}$ every 5 min until the steady state (Lambda 25, PerkinElmer, Italy). Calibration curve was obtained using 6-Hydroxy-2,5,7,8-tetramethylchroman-2-carboxylic acid (Trolox), a water-soluble analog of $\alpha$-tocopherol, 
as standard and results were expressed as mmol Trolox equivalent (TE) $\mathrm{kg}^{-1} \mathrm{FW}$. All biological replicates of samples were analyzed in triplicate.

ABTS method. 2,2'-azinobis (3-Ethylbenzothiazoline-6-sulfonic acid) (ABTS) procedure modified from Re et al. was used (1999) [36]. A concentrate solution of the reagent (stock solution) was prepared dissolving $9.6 \mathrm{mg}$ of ABTS in $2.5 \mathrm{~mL}$ of water and adding $44 \mathrm{~mL}$ of a solution made by dissolving $37.5 \mathrm{mg}$ of potassium persulphate, $\mathrm{K}_{2} \mathrm{~S}_{2} \mathrm{O}_{8}$, in $1 \mathrm{~mL}$ of water. The stock solution was kept in the dark at $4{ }^{\circ} \mathrm{C}$ for $8 \mathrm{~h}$ before use; the work solution was obtained from the stock solution by dilution using a 1:88 (v/v) ratio. Dilution was adjusted depending on the measured absorbance at $\lambda 734 \mathrm{~nm}$ (A734) in the work solution, until a value between 0.7 and 0.8 . Subsequently, $100 \mu \mathrm{L}$ of sample and $1 \mathrm{~mL}$ of work solution were added, and A734 was measured exactly after $2 \mathrm{~min}$ and $30 \mathrm{~s}$. (Lambda 25, PerkinElmer, Italy). Calibration curve was obtained using 6-Hydroxy-2,5,7,8-tetramethylchroman-2-carboxylic acid (Trolox), a water-soluble analog of $\alpha$-tocopherol, as standard and results were expressed as mmol Trolox equivalent (TE) $\mathrm{kg}^{-1} \mathrm{FW}$. All biological replicates of samples were analyzed in triplicate.

\section{Conclusions}

Our results confirmed the ability of the Trichoderma harzianum (strain T22) and its metabolites (6PP and HA) in the defense system of the Olea europaea tree and demonstrate that the ABTS test is the preferred method for determining the antioxidant activity in the EVOO. To the best of our knowledge, the present work is the first report that correlates the nutraceutical properties of the EVOO to a specific biostimulation method used in the field. Our results suggest new possibilities of using Thricoderma and its metabolites to select the nutraceutical properties of the EVOO and recommend the use of Thricoderma metabolites in olive tree cultivation to avoid some of the limitations related to the application of living microbes.

Author Contributions: Formal analysis and writing-original draft preparation, I.D.; data curation, G.G.; data curation, A.G.; formal analysis, F.L.F. and P.C.; investigation A.S. and M.L.; formal analysis and writing, F.V.; project administration, A.R. All authors have read and agreed to the published version of the manuscript.

Funding: The following projects supported this work: MIUR (Ministry of Education, University and Research)—PON (National Operational Program) [grant number Linfa 03PE_00026_1], [grant number Marea 03PE_00106]; POR (Regional Operational Program) FESR ((European Regional Development Fund) Campania 2014-2020 [grant number Bioagro NR. onc3-003189].

Conflicts of Interest: The authors declare no conflicts of interest.

\section{References}

1. Servili, M.; Sordini, B.; Esposto, S.; Urbani, S.; Veneziani, G.; di Maio, I.; Selvaggini, R.; Taticchi, A. Biological activities of phenolic compounds of extra virgin olive oil. Antioxidants 2014, 3, 1-23. [CrossRef]

2. Rigacci, S.; Stefani, M. Nutraceutical properties of olive oil polyphenols. An itinerary from cultured cells through animal models to humans. Int. J. Mol. Sci. 2016, 17, 843. [CrossRef]

3. Fabiani, R.; Rosignoli, P.; de Bartolomeo, A.; Fuccelli, R.; Servili, M.; Montedoro, G.F.; Morozzi, G. Oxidative DNA damage is prevented by extracts of olive oil, hydroxytyrosol and other olive phenolic compounds in human blood mononuclear cells and HL60 cells. J. Nutr. 2008, 138, 1411-1416. [CrossRef]

4. Tundis, R.; Loizzo, M.; Menichini, F.; Statti, G.; Menichini, F. Biological and pharmacological activities of iridoids: Recent developments. Mini Rev. Med. Chem. 2008, 8, 399-420. [CrossRef]

5. Dini, I.; Laneri, S. Nutricosmetics: A brief overview. Phytother. Res. 2019, 33, 3054-3063. [CrossRef]

6. Tafuri, S.; Cocchia, N.; Carotenuto, D.; Vassetti, A.; Staropoli, A.; Mastellone, V.; Peretti, V.; Ciotola, F.; Albarella, S.; Del Prete, C.; et al. Chemical Analysis of Lepidium meyenii (Maca) and Its Effects on Redox Status and on Reproductive Biology in Stallions. Molecules 2019, 24, 1981. [CrossRef]

7. Alarcón de la Lastra, C.; Barranco, M.D.; Motilva, V.; Herrerías, J.M. Mediterranean diet and health: Biological importance of olive oil. Curr. Pharm. Des. 2001, 10, 933-950. [CrossRef]

8. Servili, M.; Selvaggini, R.; Esposto, S.; Taticchi, A.; Montedoro, G.; Morozzi, G. Health and sensory properties of virgin olive oil hydrophilic phenols: Agronomic and technological aspect of production that affect their occurence in the oil. J. Chromatogr. 2004, 1054, 113-127. [CrossRef] 
9. EC (2017) EU funding under the new CAP. Agriculture and Rural Development. Organic Farming. Available online: https://ec.europa.eu/agriculture/organic/eu-funding/eu-funding-and-the-new-cap_en. (accessed on 27 July 2017).

10. Harman, G.E.; Howell, C.R.; Viterbo, A.; Chet, I.; Lorito, M. Trichoderma species, opportunistic avirulent plant symbionts. Nat. Rev. Microbiol. 2004, 2, 43-56. [CrossRef] [PubMed]

11. Lorito, M.; Woo, S.L.; Harman, G.E.; Monte, E. Translational research on Trichoderma: From Omics to the field. Ann. Rev. Phytopathol. 2010, 48, 395-417. [CrossRef] [PubMed]

12. Woo, S.L.; Ruocco, M.; Vinale, F.; Nigro, M.; Marra, R.; Lombardi, N.; Pascale, A.; Lanzuise, S.; Manganiello, G.; Lorito, M. Trichoderma-based products and their widespread use in agriculture. Open Mycol. J. 2014, 8, 71-126. [CrossRef]

13. Reino, J.L.; Guerrero, R.F.; Hernandez-Galan, R.; Collado, I.G. Secondary metabolites from species of the biocontrol agent Trichoderma. Phytochem. 2008, 7, 89-123. [CrossRef]

14. Pascale, A.; Vinale, F.; Manganiello, G.; Nigro, M.; Lanzuise, S.; Ruocco, M.; Marra, R.; Lombardi, N.; Woo, S.L.; Lorito, M. Trichoderma and its secondary metabolites improve yield and quality of grapes. Crop Prot. 2017, 92, 176-181. [CrossRef]

15. Agosin, E.; Aguilera, J.M. Industrial production of active propagules of Trichoderma for agricultural use. In Trichoderma and Gliocladium., Enzymes, Biological Control and Commercial Applications; Harman, G.E., Kubicek, C.P., Eds.; Taylor \& Francis Ltd.: London, UK, 1998; Volume 2, pp. 205-227.

16. Vinale, F.; Nigro, M.; Sivasithamparam, K.; Flematti, G.; Ghisalberti, E.L.; Ruocco, M.; Varlese, R.; Marra, R.; Lanzuise, S.; Eid, A.; et al. Harzianic acid: A novel siderophore from Trichoderma harzianum. FEMS Microbiol. Lett. 2013, 347, 123-129.

17. Keswani, C.; Singh, H.B.; Hermosa, R.; García-Estrada, C.; Caradus, J.; He, Y.W.; Aichour, S.M.; Glare, T.R.; Borriss, R.; Vinale, F.; et al. Antimicrobial secondary metabolites from agriculturally important fungi as next biocontrol agents. Appl. Microb. Biotech. 2019, 103, 9287-9303. [CrossRef]

18. Mastouri, F.; Bjorkman, T.; Harman, G.E. Trichoderma harzianum enhances antioxidant defense of tomato seedlings and resistance to water deficit. Mol. Plant Microbe Interact. 2012, 25, 1264-1271. [CrossRef] [PubMed]

19. Rouphael, Y.; Carillo, P.; Colla, G.; Fiorentino, N.; Sabatino, L.; El-Nakhel, C.; Giordano, M.; Pannico, A.; Cirillo, V.; Shabani, E.; et al. Appraisal of combined applications of trichoderma virens and a biopolymer-based biostimulant on lettuce agronomical, physiological, and qualitative properties under variable regimes. Agronomy 2020, 10, 196. [CrossRef]

20. Woo, S.L.; Scala, F.; Ruocco, M.; Lorito, M. The molecular biology of the interactions between Trichoderma spp., phytopathogenic fungi and plants. Phytopathology 2006, 96, 181-185. [CrossRef]

21. Klen, T.J.; Wondra, A.G.; Vrhovšek, U.; Mozetič, V.B. Phenolic profiling of olives and olive oil process-derived matrices using UPLC-DAD-ESI-QTOF-HRMS analysis. J. Agric. Food Chem. 2015, 63, 3859-3872. [CrossRef]

22. Dini, I.; Graziani, G.; Fedele, F.L.; Sicari, A.; Vinale, F.; Castaldo, L.; Ritieni, A. Effects of Trichoderma biostimulation on the phenolic profile of extra-virgin olive oil and olive oil by-products. Antioxidants 2020, 9, 284. [CrossRef]

23. Prior, R.L.; Wu, X.; Schaich, K. Standardized methods for the determination of antioxidant capacity and phenolics in foods and dietary supplements. J. Agric. Food Chem. 2005, 53, 4290-4302. [CrossRef] [PubMed]

24. Benavente-Garcia, O.; Castillo, J.; Lorente, J.; Ortuno, A.; Del Rio, J.A. Antioxidant activity of phenolics extracted from Olea europaea L. leaves. Food Chem. 2000, 68, 457-462. [CrossRef]

25. Dini, I.; Seccia, S.; Senatore, A.; Coppola, D.; Morelli, E. Development and Validation of an Analytical Method for Total Polyphenols Quantification in Extra Virgin Olive Oils. Food Anal. Methods 2020, 13, 457-464. [CrossRef]

26. Omar, S.H. Oleuropein in olive and its pharmacological effects. Sci. Pharm. 2010, 78, 133-154. [CrossRef]

27. Montesano, D.; Rocchetti, G.; Cossignani, L.; Senizza, B.; Pollini, L.; Lucini, L.; Blasi, F. Untargeted Metabolomics to Evaluate the Stability of Extra-Virgin Olive Oil with Added Lycium barbarum Carotenoids during Storage. Foods 2019, 8, 179. [CrossRef]

28. Xu, H.; Linn, B.S.; Zhang, Y.; Ren, J. A review on the antioxidative and prooxidative properties of luteolin. React. Oxyg. Species 2019, 7, 136-147. [CrossRef]

29. López-Biedma, A.; Sánchez-Quesada, C.; Delgado-Rodríguez, M.; Gaforio, J.J. The biological activities of natural lignans from olives and virgin olive oils: A review. J. Funct. Foods 2016, 26, 36-47. [CrossRef] 
30. Obied, H.K.; Prenzler, P.D.; Ryan, D.; Servili, M.; Taticchi, A.; Esposto, S.; Robards, K. Biosynthesis and biotransformations of phenol-conjugated oleosidic secoiridoids from Olea europaea L. Nat. Prod. Rep. 2008, 25, 1167-1179. [CrossRef]

31. Marín, L.; Gutiérrez-del-Río, I.; Yagüe, P.; Manteca, Á.; Villar, C.J.; Lombó, F. De novo biosynthesis of apigenin, luteolin, and eriodictyol in the Actinomycete Streptomyces albus and production improvement by feeding and spore conditioning. Front. Microbiol. 2017, 8, 921. [CrossRef]

32. Vázquez Roncero, A. Les polyphe'nols de l'huile d'olive et leur influence sur les caracte'ristiques de l'huile. Rev Franç Corps Gras 1978, 25, 21-26.

33. AOAC (2012) Appendix F: cGuidelines for Standard Method Performance Requirements (SMPR). AOAC Official Methods of Analysis. Available online: http://www.eoma.aoac.org/app_f.pdf. (accessed on 1 May 2020).

34. Singleton, V.L.; Rossi, J.A. Colorimetry of total phenolics with phosphmolybdic phospotungstic acid reagents. A J. Enol. Vitic. 1965, 16, 144-158.

35. Brand-Williams, W.; Cuvelier, M.E.; Berset, C. Use of a free radical method to evaluate antioxidant activity. Lwt - Food Sci. Technol. 1995, 28, 25-30. [CrossRef]

36. Re, R.; Pellegrini, N.; Proteggente, A.; Pannala, A.; Yang, M.; Rice-Evans, C. Antioxidant activity applying an improved ABTS radical cation decolorization assay. Free Radic. Biol. Med. 1999, 26, 1231-1237. [CrossRef]

Sample Availability: Samples of the oil and phenolic extracts are available from the authors. 